\title{
“ME ERIJO VOZ DESDE EL SILENCIO": LAS MUJERES ESCRITORAS EN LOS MANUALES DE EDUCACIÓN SECUNDARIA (EL CASO DE LA MAREA VERDE)
}

\section{"ME ERIJO VOZ DESDE EL SILENCIO": WOMEN WRITERS IN SECONDARY EDUCATION TEXTBOOKS (THE CASE OF "LA MAREA VERDE")}

\author{
Raúl Molina Gil \\ raul.molina@uv.es \\ Departamento de Teoría de los Lenguajes y Ciencias de la Comunicación. \\ Universidad de Valencia (España)
}

Recibido: $14 / 04 / 2020$

Aceptado: 27/12/2020

\begin{abstract}
Resumen:
En un momento como el actual, en el que la pedagogía y la enseñanza buscan nuevos modelos fundamentados en la inclusión y en la igualdad, es vital pensar cómo, de qué forma y en qué cantidades son representadas las mujeres escritoras en los manuales dirigidos a la enseñanza de la lengua y la literatura en la educación secundaria. En las páginas que siguen, reflexionaremos desde el punto de vista del género sobre el canon literario que se transmite en las aulas de educación secundaria a través del análisis de la nómina de autoras y autores estudiados y del tratamiento que estas y estos reciben en los libros de texto de la Marea Verde, adaptados al currículum educativo de la Comunidad de Madrid y publicados bajo licencia Creative Commons 3.0 by-nc-sa en su página web.
\end{abstract}

Palabras clave: Análisis de Manuales, Educación Secundaria Obligatoria, Educación Inclusiva, Literatura Española, Género

\begin{abstract}
:
Today, the pedagogy and the teaching are looking for new inclusive and equality models. For this reason, it is fundamental to think how the women writers are represented into the language and literature secondary school textbooks. In the next pages, based on genre theories, we will reflect on literary canon which is transmitted in the secondary school classes. In this sense we will analyze the inventory and the treatment of women and men writers that are studied into the Marea Verde textbooks, which are adapted to the educational laws of the Comunidad de Madrid and were published under a Creative Commons 3.0 by-nc-sa license in his own website.

Key Words: Textbook Analysis, Secondary School, Inclusive Educations, Spanish Literature, Genere
\end{abstract}


A l'atzar agraeixo tres dons: haver nascut dona, de classe baixa i nació oprimida.

I el tèrbol atzur de ser tres voltes rebel.

MARIA-MERCÈ MARÇAL

\section{Introducción y método: notas teóricas y metodológicas}

Al fin y al cabo, la problemática sobre la inclusión e invisibilización de las autoras en los manuales ${ }^{1}$ de educación secundaria obligatoria es una cuestión sobre la construcción androcéntrica del canon. Por consiguiente, el debate con los citados libros de texto no solo nos va a permitir evaluar las herramientas que lo perpetúan o proponer alternativas mediante la incorporación de escritoras, sino sobre todo desentrañar sus mecanismos de funcionamiento (en ocasiones invisibilizados) y analizar sus tangibles consecuencias. Así entendido, el canon implica un proceso de inclusión y exclusión en el que participan diversas instituciones (escuela, Universidad, etc.), junto a un muy nutrido número de agentes (autores, críticos, historiadores, etc.) cuyo trabajo conjunto permite formular ese listado de obras y autores que acaben por copar los espacios centrales del sistema literario. Debemos destacar que no tomaremos de aquí en adelante los conceptos canon y canónico, sino las alternativas propuestas por Even-Zohar, canonización y canonizado (Even-Zohar, 1990), para subrayar que la canonicidad no es una característica inherente a los textos, sino una categoría que depende de los procesos históricos (Iglesias, 1994: 332). Lo canonizado, así entendido, "no es un hecho ni biológico ni transhistórico, sino una construcción discursiva contingente, y resultado de prácticas discursivas sobredeterminadas" (Zavala, 2002: 3).

Precisamente, el discurso patriarcal es una de las principales herramientas que ha vertebrado y vertebra el entramado ideológico que define, construye y constituye los procesos de canonización, a partir del establecimiento de una matriz en la que el varón es ubicado en las posiciones de poder, mientras que la mujer ocupa los espacios de subordinación. Dicha matriz, en lo social y en lo literario, responde al modelo de la dominación masculina, teorizado por Bourdieu, que comporta una reducción de lo real a la oposición masculino/femenino: al hombre corresponde el campo de lo exterior, de lo oficial y de lo público, mientras que la mujer queda situada en el campo de lo interno, de lo abajo, de la curva y de lo continuo, y le son adjudicados los trabajos domésticos, es decir, privados y ocultos (2000: 45). Es esta, por tanto, una matriz violenta, en el sentido que Judith Butler (2006) dio al término: en otras palabras, los conceptos sexo, género o deseo han sufrido violentos procesos de naturalización a través de los cuales han sido creados sistemas jerárquicos binarios del tipo hombre/mujer o masculino/femenino que han acabado por devenir socialmente en la única taxonomización posible de lo real. Frente a ello, la praxis y la crítica, entendidas como los mecanismos que permiten modificar esa "fábrica de género construido de forma paralela a la modernidad" (Nash, 2004: 22), persiguen restaurar "a la mujer la propiedad de sus cuerpos" (Firestone, 1995: 12) y, en un desplazamiento hacia la literatura, "repensar los sistemas axiológicos que sustentan las categorías legitimadas sobre lo literario [...] [y] los procedimientos empleados para configurar tal historia" (Fariña Busto, 2016: 15).

\footnotetext{
1 Utilizaremos indistintamente los términos "manuales" y "libros de texto", entendidos como aquellos volúmenes que «nombran las distintas actividades de la escuela, discursos, disciplinas, acciones, procesos, objetivos, y muchas veces su preocupación es la educación en general" (Quiceno, 2001: 54-55).
} 
En este sentido, si la historiografía literaria ha deslegitimado a las mujeres escritoras a partir de un discurso que ha brotado de la matriz de dominación masculina, es de suponer que los libros de texto de secundaria (que no hacen, como dijera Blanco García, "más que reproducir visiones y concepciones dominantes" [2000: 14]) repitan estos esquemas, perpetuando y naturalizando así una fotografía con muy pocos rostros de mujer, como ya apuntaron Nuria Garreta y Pilar Careaga (1987), Maribel García García (1993) o Ana López-Navajas (2015). Hablamos, por tanto, de una política de borrado y expulsión que se utiliza diversos mecanismos, como los analizados por Joana Russ en How to suprees Women's Writing en 1983 y que todavía siguen vigentes: prohibiciones de acceso a las herramientas de la escritura, desautorización o devaluación, desacreditación de la calidad literaria, denegación de la autoría, falsa catalogación en tanto subordinadas a los hombres de su entorno (marido, amante, hermano, etc.), el doble estándar de contenido según el cual las experiencias masculinas son más valiosas que las femeninas, el logro aislado cuando se afirma que en un momento dado de su carrera tuvo un momento de brillantez o lucidez, la excepcionalidad a la norma, la falta de modelos, la degradación de la imagen y el rechazo de identidad. Dicha política se ubica en la intersección entre, primero, el ámbito educativo obligatorio y legislado desde los poderes estatales y autonómicos (como analizara García-Luque al estudiar el carácter heterosexista de la LOMCE [2016]); segundo, la institución literatura, de cariz autónomo (Bourdieu, 1994 y Dubois, 2014) y, a su vez, utilizada como aparato ideológico del estado (Althusser, 1974); $y$, tercero, la "industria editorial" (Adorno y Horkneiner, 1998) que mercadea con los libros de texto.

En vista de lo dicho, es necesario profundizar en los manuales desde una perspectiva de género que nos permita establecer una crítica, entendida a la manera de Foucault, como el mecanismo que poseemos para no ser gobernados, o incluso, para no ser gobernados de esa forma y a ese precio (2006: 8). Para ello, no solo debemos valernos del análisis textual, sino que se antoja necesario ampliarlo con un estudio cuantitativo, lo cual nos permitirá ofrecer una imagen más detallada sobre el tema que aquí nos concierne. Así pues, ante la necesidad de establecer unas variables para el análisis, recurriremos a las categorías manejadas por Ana López-Navajas (2015) que definen el lugar y el modo de aparición de las autoras y autores en los libros de textos.

En lo que respecta al lugar de aparición, manejamos las variables (López-Navajas, 2015: 95-96): cuerpo (información que se debe conocer y que constituye la parte central del tema; es el lugar más relevante); actividades (conjunto de ejercicios); anexos (información de carácter subsidiario muchas veces no utilizada; último lugar en importancia).

En lo referente al modo de aparición, manejamos las variables (López-Navajas, 2015: 9697): reseñado (información a la que se dedican varios párrafos o páginas); citado (la información que aparece es únicamente el nombre); obra original (se incluye una lectura de la obra original); ilustración (fotografía, cuadro o imagen).

\subsection{Breve descripción de los manuales de educación secundaria de la Marea Verde}

Según la Marea Verde, los contenidos de estos cuatro libros de texto han sido elaborados teniendo en cuenta que los cursos de primero y segundo de educación secundaria obligatoria, por un lado, y de tercero y cuarto, por otro, forman dos ciclos diferenciados, de modo que estos están distribuidos en cada curso de forma gradual evitando la repetición innecesaria). Para ello, dicen, se tuvo en cuenta en currículum educativo establecido por la Comunidad de Madrid en el Real Decreto 23/2007, de 10 de mayo, aunque posteriormente los contenidos han sido actualizados siguiendo las indicaciones de la LOMCE y del currículum autonómico elaborado a partir de ella, es decir, el Decreto 48/2015, de 14 de mayo, del Consejo de Gobierno, por el que se establece para la Comunidad de Madrid el currículo de la Educación Secundaria Obligatoria. 
Cada uno de los manuales analizados está subdividido en tres bloques: uno de ellos, de contenido gramatical; otro, vinculado a la comunicación y las variedades de la lengua; el tercero, dedicado a la literatura. A su vez, estos pueden ser ampliados con los anexos, en los que encontramos material sobre literatura y sobre gramática. En lo referente a los apartados sobre literatura, hay que destacar que mientras los manuales de primero y segundo de la ESO focalizan en el estudio de los géneros literarios, los de tercero y cuarto se centran en la historia de la literatura, por lo que no es de extrañar que en estos últimos encontremos más referencias a autoras y autores ${ }^{2}$.

\section{Análisis cuantitativo: una reflexión sobre los datos extraídos}

Los primeros datos que hemos extraído son los referidos a las menciones totales de escritores y escritoras en los cuatro manuales de educación secundaria de la Marea Verde (en adelante, manuales de la ESO). En este sentido, nos encontramos con un total de 510 menciones, de las cuales 472 corresponden a hombres y 38 a mujeres. Esto es, en valores porcentuales, un $93 \%$ frente a un $7 \%$ (fig. 1).

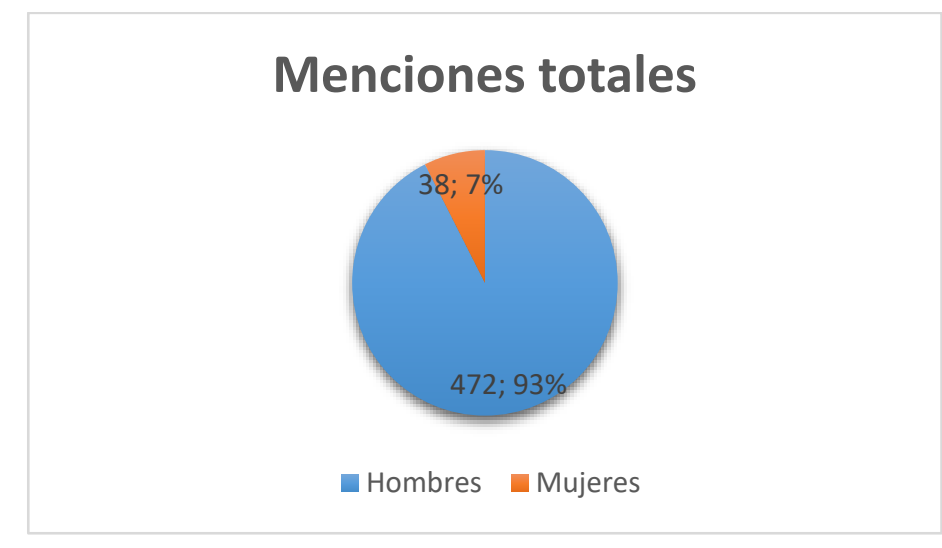

Fig. 1. Menciones totales de autores y autoras en los cuatro libros analizados

Las menciones por curso ofrecen valores muy similares a los que ofrece la gráfica anterior, como observamos en la Figura 2. En este sentido, el libro de texto de primero de ESO presenta 83 menciones de hombres y 5 de mujeres ( $94 \%$ y $6 \%$ ); el de segundo de ESO, 92 de hombres y 4 de mujeres ( $96 \%$ y $4 \%$ ); el de tercero de ESO, 92 de hombres y 3 de mujeres ( $97 \%$ y $3 \%$ ); y el de cuarto de ESO, 205 de hombres y 26 de mujeres ( $89 \%$ y 11\%). Los datos totales en el libro de texto de cuarto de la ESO se multiplican, debido muy probablemente a la cercanía temporal y al auge de publicaciones que se dio en este periodo de la historia literaria gracias al avance tecnológico del que ya hablaran Adorno y Horkheiner al referirse a la "industria cultural" (1988) y Benjamin en La obra de arte en la época de su reproductibilidad técnica (2003).

\footnotetext{
2 Para observar en detalle la estructura de los libros comentados, remitimos a la página web de La Marea Verde: https://sites.google.com/site/librosmareaverde/lengua. En la bibliografía de este artículo, los manuales vienen citados a partir de las siglas VV.AA: 2015a corresponde al manual de 30; 2015b, al de cuarto; 2017a, al de 10; 2017b, al de segundo. Para facilitar su referencia, utilizaremos el siguiente modelo, según el curso al que nos referimos: MV1ESO, MV2ESO, MV3ESO y MV4ESO.
} 


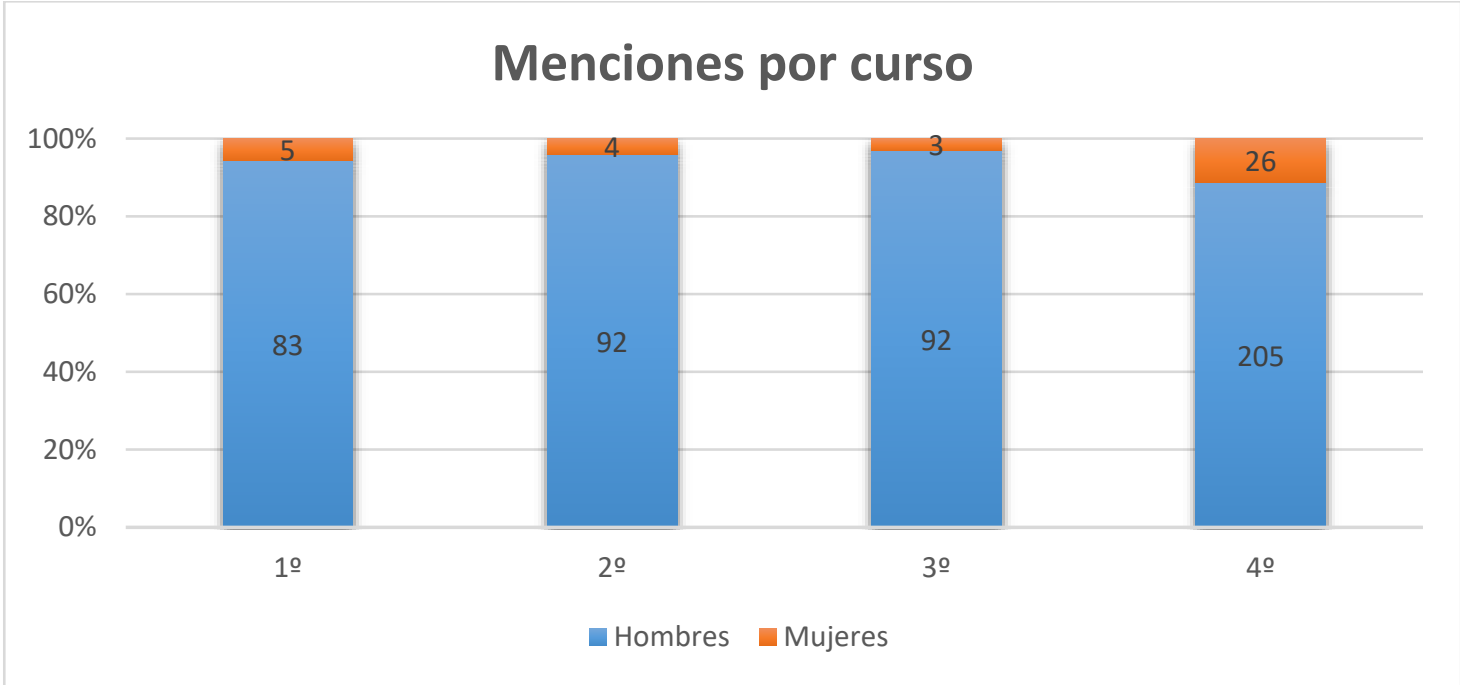

Fig. 2. Menciones totales de autoras y autores por curso

Es necesario, a la hora de comentar estos datos, tener en cuenta la estructuración por apartados comentada en las páginas anteriores. En este sentido, los libros de texto de primero y segundo son menos específicos, ya que focalizan en el estudio de los géneros literarios, de las herramientas propias de cada uno de ellos, de sus características, etc. Por su parte, los manuales de tercero y cuarto de la ESO presentan sendos recorridos por la historia literaria de España: el de tercero, desde la Edad Media hasta el siglo XVII; el de cuarto de la ESO, desde aquí hasta la actualidad. Así pues, la inmensa mayoría de menciones que encontramos en los dos primeros libros corresponden mayoritariamente a ejemplos sobre los contenidos estudiados o a obras originales a partir de las cuales se proponen ejercicios. En los dos segundos, por otro lado, nos encontramos también con esta práctica, a la que se añade un recorrido histórico, de forma que buena parte de las menciones se corresponden con los autores y obras canonizados en cada uno de los periodos. A pesar de estas diferencias de contenido, podemos ya apuntar que, en cualquier caso, la imagen que ambos manuales transmiten al alumnado es la de una historia literaria dominada por los hombres, en la que las mujeres tienen roles muy secundarios y marginales.

Además del total, debemos también presentar los datos a partir de las variables tomadas de Ana López Navajas (2015). En primer lugar, presentamos en la siguiente tabla las menciones totales según lugar de aparición de hombres y mujeres en los cuatro manuales estudiados (Fig. 3):

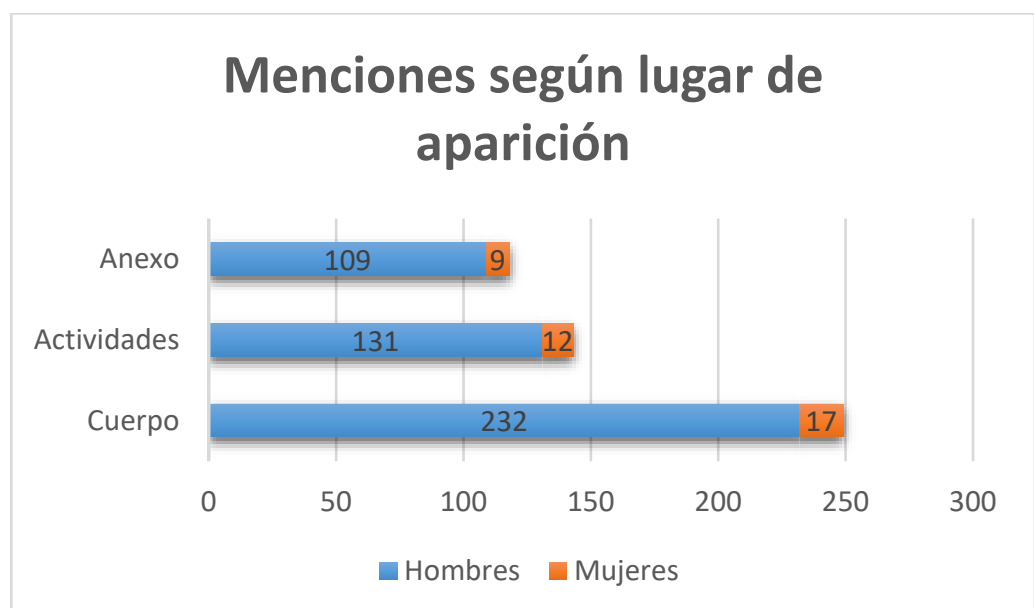

Fig. 3. Menciones totales de autores y autoras según el lugar de aparición 
En este sentido, del total de 472 menciones de hombres, el 23,09\% (109) aparecen en los lugares con menos importancia, es decir, los anexos; el 27,75\% (131) lo hacen en las actividades planteadas al alumnado, cuya realización es opcional y depende del criterio del profesorado; finalmente, el 49,16\% (232) aparecen en el cuerpo del texto que, como se ha comentado, es el lugar de mayor importancia. En el caso de las mujeres, del total de 38, el 23,68\% (9) aparecen en los anexos, el $31,57 \%$ (12) en las actividades y el $44,75 \%$ (17) en el cuerpo (Fig. 3). Si nos fijamos en la relación entre escritores y escritoras, observamos en los anexos nos encontramos con un $8,2 \%$ de escritoras, un $9,16 \%$ en las actividades y únicamente un $7,2 \%$ en el cuerpo del texto, que es el espacio más importante según los hemos definido en la metodología de este trabajo. Observamos los mismos detalles al separar los datos según el lugar de aparición por curso (Figs. 4, 5, 6 y 7), con la consabida diferencia de que las menciones en 4. de la ESO son más numerosas (Fig. 7).

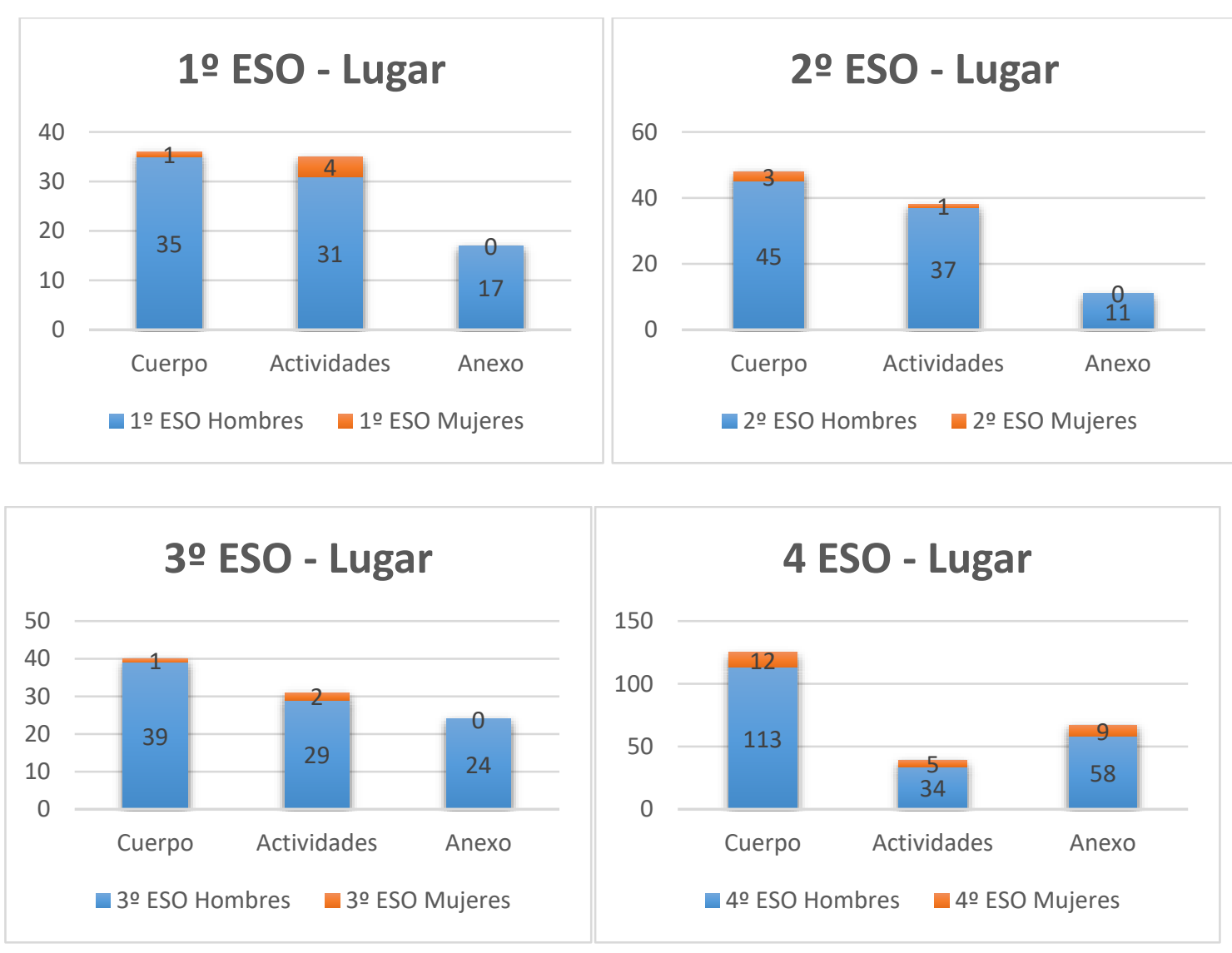

En cuanto a la forma de aparición, de las 510 menciones totales, 51 pertenecen al apartado "Reseñado", 203 al "Citado", 240 a "Obra original" y 16 a "Ilustración". Estas, a su vez, se pueden subdividir entre hombres y mujeres (Fig. 8) 


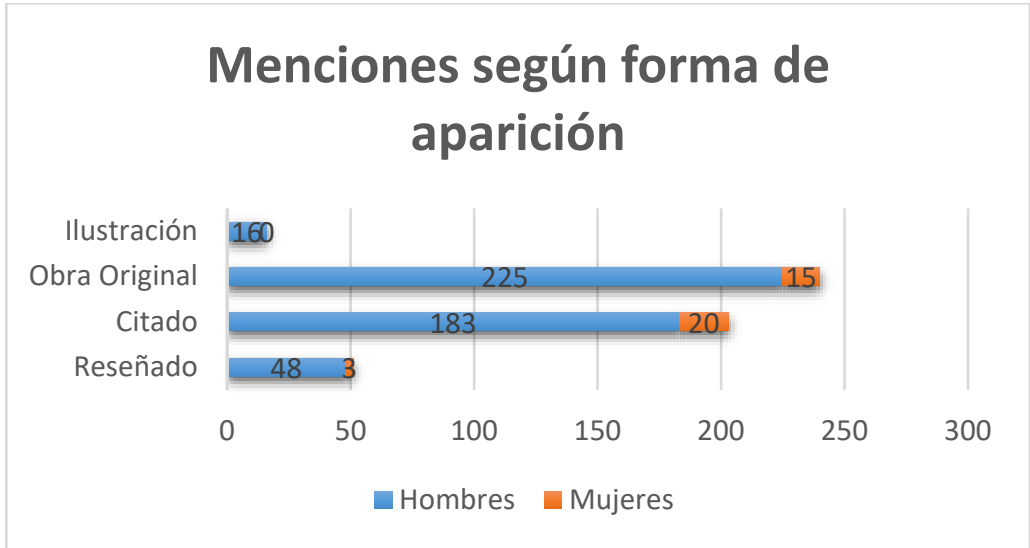

Fig. 8. Menciones totales de autores y autoras según la forma de aparición

Porcentualmente, el $100 \%$ de las ilustraciones son de hombres ( 16 frente a 0 ); el $93,75 \%$ de las obras originales son de hombres y el $6,25 \%$ de mujeres; el $90,14 \%$ de las menciones citadas son de hombres, frente al 9,86\% de mujeres; en cuanto a los elementos reseñados, el $94,10 \%$ son de hombres y el 5,90\% de mujeres (Fig. 8). En este sentido, son muy significativas la focalización masculina en las ilustraciones y la amplia diferencia en el apartado de elementos reseñados, el más importante en este sentido. Ello indica una puesta en primer término de lo masculino en lo que respecta al valor de las apariciones. A continuación, presentamos el desglose por libros en unas gráficas que responden a las menciones totales de autoras y autores según la forma de aparición en los manuales (Figs. 9, 10, 11 y 12):
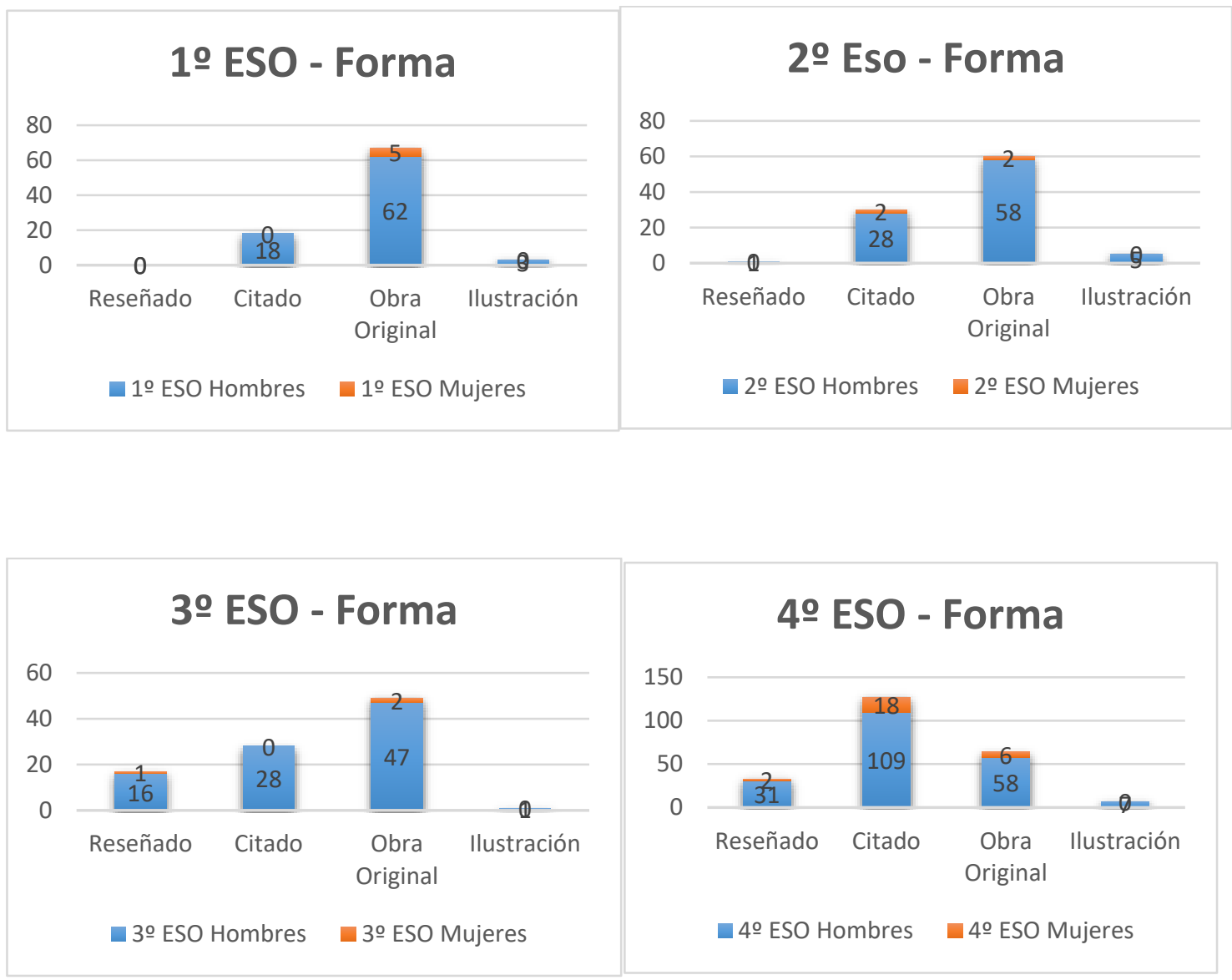
Como se puede deducir de los datos anteriores, todavía hoy observamos que los libros de texto de secundaria como los que aquí estamos analizando perpetúan una visión atravesada por un discurso patriarcal que envía al alumnado el implícito mensaje de que los libros que merecen ser recordados y estudiados fueron escritos en su inmensa mayoría por hombres: un $93 \%$ frente a un $7 \%$. Esta amplísima diferencia manifiesta a las claras la existencia de una ideología fundamentada en la dominación masculina que ha ubicado, y sigue haciéndolo, a las mujeres en el margen de las parcelas sociales y a los hombres en el centro de las mismas, entronizando su presencia, su voz y su imagen: "todo discurso de miles de años sobre la mujer de ninguna manera puede ser considerado neutral" (Bourdieu, 2000: 20), lo cual incluye, por supuesto, al discurso literario y a sus procesos de canonización, que quedan instalados del lado del discurso masculino de la ecuación (Bourdieu, 2000: 21). De lo que se trata, por lo tanto, es de "descolonizar el canon del patriarcado, de re-apropiarlo y re-escribir las culturas restaurando sus silencios y las políticas y la lucha por el poder inscritos en los textos" (Zavala, 1993: 28), en un movimiento de epistemología responsable que ponga al descubierto algunas de las mentiras pasadas por grandes verdades (Zavala, 1993: 28).

Es sintomático que esos silencios estén habitualmente habitados, en primer lugar, por escritores heterodoxos cuyas prácticas literarias fueron excesivamente rupturistas o críticas con el sistema de valores y que, considerados peligrosos, no pudieron participar de los procesos de canonización, quedando relegados al estudio especializado por parte de investigadores universitarios (es el caso, por ejemplo, de buena parte de las vanguardias literarias de los años veinte y treinta). En segundo lugar, por aquellos escritores que no formaron parte de las corrientes mayoritarias y que no pudieron, por ello, entrar en los cauces de difusión, es decir, caminantes solitarios que todavía hoy están fuera de las fotografías generacionales que con tanta profusión decoran las páginas de los manuales de literatura (como ejemplo paradigmático, quizás, aquella de la Generación del 27 durante el homenaje a Góngora). En tercer lugar, aquellos que se consideró que estética y estilísticamente no estaban al nivel de sus contemporáneos y que, por estas razones, quedaron relegados a un segundo plano ya durante el propio momento histórico de la escritura.

$\mathrm{Y}$, por supuesto, las mujeres, condenadas, como hemos visto en las páginas anteriores, a no ser reconocidas por sus colegas varones, que, en la inmensa mayoría de los casos, fueron los principales constructores y valedores de los procesos de canonización desde sus puestos de poder en la crítica literaria, en la universidad, en las instituciones, etc. En este sentido, únicamente unas pocas elegidas han sido recogidas en las nóminas generacionales de estos manuales, en un claro trasunto de lo que han venido realizando las historias literarias en nuestro país: en Lengua y literatura 1. ESO las mujeres incluidas son Shakira (51), Elvira Lindo (64), Christine Nöstlinger (71) y Gloria Fuertes (81 y 90); en Lengua y literatura 2.․ ESO encontramos de nuevo a Gloria Fuertes (114), Rosalía de Castro (116 y 117) y J. K. Rowling (127); en Lengua y literatura 3. ESO se nos presenta a Santa Teresa de Jesús (131 y 136) y Sor Juana Inés de la Cruz, en los anexos (152); finalmente, en Lengua y literatura 4. ESO, Rosalía de Castro (96, 101 y 106), Emilia Pardo Bazán (101), María Zambrano (117), Ana María Matute (118), Carmen Martín Gaite (118), Isabel Allende (127), Marcela Serrano (127), Gioconda Bello (127), Gabriela Mistral (128), Alfonsina Storni (128), Blanca Andreu (130), Juana Castro (130), Olvido García Valdés (130), Amparo Amorós (130), Almudena Grandes (132 y 133), Ana Diosdado (133), Ana Rossetti (134) y, en los anexos, Dulce María Loynaz (162), Laura Esquivel (164) y Carmen Gómez Ojeda (166-167).

A su vez, suelen responder a unas características que podemos nombrar con relativa facilidad: habitualmente son aquellas escritoras en las que se combinó tanto la posición de poder social que ocuparon en cada uno de los momentos históricos como la calidad literaria de sus obras. Este supuesto está claramente reflejado en estos libros de texto con los casos paradigmáticos de Emilia Pardo Bazán, de familia burguesa; de Carmen Martín Gaite, de familia de profesores 
universitarios y de juristas; de Ana María Matute, proveniente de la pequeña burguesía catalana; de Isabel Allende, hija de un diplomático y sobrina segunda del presidente Salvador Allende; o de Gabriela Mistral, de familia de propietarios de tierras en su Chile natal. Si nos retrotraemos varios siglos atrás, un amplio porcentaje de las mujeres que han conseguido permanecer en la historia literaria y aparecer en este tipo de manuales pertenecieron a la élite eclesiástica, que funcionó como herramienta legitimadora y difusora para autoras como Santa Teresa de Jesús o Sor Juana Inés de la Cruz, también incluidas en los manuales, quienes además tuvieron desde ese espacio la posibilidad de entrar en contacto con el mundo de la cultura. Por último, las hay que consiguieron hacerlo superando trabas sociales que no tuvieron sus colegas escritores: Gloria Fuertes, nacida en una humilde familia del barrio de Lavapiés, e incluida en varios de los manuales, o María Zambrano, cuyos padres eran maestros de profesión.

Otras, han sido rescatadas con posterioridad, gracias a las recientes, y tan necesarias, reediciones de sus obras, a las que se ha dedicado una parte de la actual crítica, habitualmente desde el ámbito universitario (Luisa Carnés es un ejemplo reciente, gracias a la Editorial Hoja de Lata, las Sinsombrero, a las que, además, les fue dedicado un capítulo de Imprescindibles y fueron protagonistas del episodio décimo de la segunda temporada de la popular serie $E I$ Ministerio del Tiempo, etc.). Sin embargo, pese a los esfuerzos, es fundamental un trabajo más intenso, influyente y de un recorrido mucho mayor para situar a estas escritoras en el lugar que la historia literaria les negó por el mero hecho de ser mujeres y, por consiguiente, para hacerlas entrar en los manuales de la ESO.

Así pues, podemos atestiguar que en los manuales de la ESO de la Marea Verde no solo priman la voz de los varones, sino que seleccionan a un nutrido grupo de mujeres que pertenecieron a las élites sociales, culturales e intelectuales de sus épocas, sin hacer referencias explícitas a las causas que permitieron que sus obras pudieran darse a conocer. $Y$ lo hacen, precisamente, porque dichos manuales se establecen sobre los discursos (heteropatriarcales) que han sustentado las historias de la literatura.

En este sentido, resulta necesario repensar el objeto literario y reformular su historia desde los presupuestos del feminismo, en tanto ejercicio de justicia, pero, sobre todo, en la medida en que ello nos va a permitir cuestionar los procesos materiales e ideológicos que se llevaron y se llevan a cabo. Es esta, como dijera Iris Zavala, una lectura con sospecha (recordando a Marx, a Nietzsche y a Freud) que se replantea lo que dicen y lo que callan los diferentes discursos culturales y que trata de desmontar las matrices los grandes relatos legitimadores (Zavala, 1995: 12). Siguiendo su misma senda:

Se trata de sospechar de las verdades o las ficciones o las mentiras que los textos emiten mediante signos ambivalentes, y de subvertir sistemáticamente las jerarquías con la más lúcida conciencia de la imposibilidad de trascender las oposiciones o las diferencias escritas en los textos, para arrellanarnos en el reino de los valores absolutos [...] Interpretar es una digresión creativa sobre los relatos maestros, en una textualización de la historia que intenta recuperar las voces reprimidas y las zonas y capas de espesor sin definir. (Zavala, 1995: 18)

\section{Análisis textual: el tratamiento de las mujeres escritoras en los manuales de educación secundaria de la Marea Verde}

\subsection{Lengua y literatura 1. ESO y Lengua y literatura 2. ESO}

En primer lugar, tomamos los manuales de 1. y 2. de ESO en conjunto, puesto que, como se ha mencionado con anterioridad, conforman una primera unidad en cuanto a los contenidos, ya 
que focalizan en el estudio general de los géneros literarios, de las figuras y tropos, de los tipos de estrofas, etc.

Si nos centramos en Lengua y literatura 1. ESO, observamos que, curiosamente, la primera de las mujeres que aparece es la famosa cantante colombiana Shakira. Lo hace a través de una obra original ("Que vuelvas"), a partir de la cual se le pide al alumnado que reflexione sobre los recursos literarios utilizados (MV1ESO, 51). En segundo lugar, Elvira Lindo aparece en el cuerpo del texto a partir de un pequeño extracto de su obra Manolito on the road, que permite ejemplificar la narración en primera persona (MV1ESO, 64). A continuación, nos encontramos con un texto de Christine Nöstlinger en unas actividades sobre los subgéneros narrativos (MV1ESO, 71). Finalmente, Gloria Fuertes aparece en dos ocasiones: en unas actividades para determinar si una serie de textos presentados pertenecen o no al género teatral (MV1ESO, 81) y en las actividades de repaso del bloque, en las que son propuestos una serie de ejercicios a partir de su famoso poema "Nota biográfica". La figura de Gloria Fuertes vuelve a aparecer en Lengua y literatura 2. ESO para ejemplificar a partir de unos versos la figura del polisíndeton (MV2ESO, 114). A continuación, en un brevísimo repaso en apenas dos páginas de la historia de la poesía española, aparece mencionada Rosalía de Castro (MV2ESO, 116), justo antes de proponer una de sus composiciones como lectura en una de las actividades diseñadas (MV2ESO, 117). Finalmente, la conocidísima J.K. Rowling, creadora de Harry Potter, permite ejemplificar una reflexión sobre los lugares de la acción, en un claro intento de incluir un referente conocido por el alumnado: "En ocasiones, los escenarios imaginarios se mezclan con los reales, dando una sensación de verosimilitud. Un ejemplo conocido de esto son las novelas de Harry Potter, de la autora J. K. Rowling" (MV2ESO, 126).

Debido a que en ambos casos el bloque de literatura en estos manuales es un acercamiento a los géneros literarios, la mayoría de autoras están incluidas a partir de obras originales que permiten explicar la teoría o ponerla en práctica en los ejercicios y actividades. En este sentido, la diferencia que salta a la vista no es tanto el lugar que ocupan dentro del libro, sino el reducidísimo número de menciones, tal y como se ha visto con anterioridad.

En algunos apartados de ambos manuales es tratado el tema de la mujer. Sucede, por ejemplo, en una breve nota explicativa del Realismo decimonónico:

Con la llegada del Realismo, encontramos ya mujeres, si no como heroínas, sí, al menos, en el papel protagonista de las novelas. Eran heroínas, sin duda, debido a que eran mujeres cultas para esa época, que daban importancia al amor verdadero sobre todas las cosas, con valor para enfrentarse a lo socialmente establecido y para sufrir la crítica de la sociedad en que viven: Madame Bovary, La Regenta o Ana Karenina. (MV1ESO, 69)

Parecen obviar, sin embargo, que las tres obras fueron escritas por varones (Gustave Flaubert, Clarín y León Tolstói) y que tal heroicidad femenina no conduce a su liberación: Emma Bovary se suicida, al igual que Ana Karenina; Ana Ozores, por su parte, es vencida por la vulgaridad de Vetusta y, en consecuencia, es marginada.

En una nota anexa titulada «Saber más» se nos ofrece una comparación entre los superhéroes y las superheroínas, en un intento de acercar la reflexión al campo de conocimiento del alumnado que, pese a sus supuestas pretensiones, no hace sino subordinar el papel de las mujeres o mostrarlas como la causa del fracaso o de las dificultades de los personajes protagonistas masculinos:

Los superhéroes del cómic son solitarios, hábiles, triunfadores, y se esconden en algún disfraz para no mostrar su identidad Batman, Spiderman... A su lado aparecen las superheroínas, como complemento del hombre. A menudo se las trata como un apoyo y su papel es secundarios (Supergirl o Catwoman), o como mujeres fatales que quieren impedirles conseguir sus metas. (MV1ESO, 69) 
Un poco más adelante, se proponen una serie de actividades que permiten pensar sobre la violencia contra las mujeres a partir de un fragmento de La zapatera prodigiosa de Federico García Lorca (MV1ESO, 77).

A modo de justificación de las escasas apariciones de mujeres escritoras, en el manual de segundo de ESO se incluye un breve texto en el que conviene detenerse. Leemos:

Hasta el s. XIX, muy pocas han sido las mujeres escritoras, actrices o directoras que han pasado a la historia de nuestra literatura. Eso no quiere decir que no hayan existido. Muchas han sido las dificultades con las que estas mujeres se enfrentaban. Durante mucho tiempo, la mujer tuvo prohibido participar en obras teatrales. Incluso se podía encarcelar a la compañía o cerrar el teatro. (MV2ESO, 148)

Aunque centrado en el ámbito teatral, sus palabras bien podrían funcionar como justificación global de la ausencia. Cierto es que pocas mujeres escritoras han conseguido entrar en los procesos de canonización de la historia literaria española, tal y como dice el texto, y que muchas han sido las dificultades que han encontrado en una sociedad patriarcal como la que hemos habitado y habitamos. Ahora bien, cierto es también que el libro de texto únicamente hace referencia a esta ausencia en este texto ubicado en los anexos y que no abre la posibilidad de reflexión al alumnado para que pueda comprender las causas y razones históricas de este borrado.

\subsection{Lengua y literatura 3. ESO y Lengua y literatura 4. ESO}

El análisis de Lengua y literatura 3.o ESO nos permite realizar una reflexión más detallada, ya que plantea un estudio de la historia de la literatura desde la Edad Media hasta el Barroco en la que podemos no solo estudiar las citaciones, reseñas y obras originales que aparecen, sino cuestionarnos sobre las ausencias y sobre las diferencias en el tratamiento con respecto a los varones.

En este sentido, hay una ausencia total de mujeres en la «Unidad 7. Literatura Medieval», con lo cual se ofrece un panorama totalmente masculino en el que resaltan los canonizados Gonzalo de Berceo, el Arcipreste de Hita, Juan de Mena, el Marqués de Santillana y Alfonso X. En la "Unidad 8. Siglo XV y Renacimiento», entre la amalgama de nombres masculinos como los de Fernando de Rojas, Fray Luis de León, Garcilaso de la Vega o San Juan de la Cruz, nos encontramos con dos menciones a Santa Teresa de Jesús, que funcionan a modo de justificación de la ausencia manifiesta de mujeres: "Santa Teresa de Jesús es una de las primeras escritoras famosas. Su ejemplo sirvió a muchas mujeres en los siglos posteriores" (MV3ESO, 131), dice la primera. En la segunda, se afirma: "Muchas mujeres poetas se encontraron con el problema de un código poético muy estricto, en el cual se describía a una dama que no correspondía al amor. Algunas escribían como si fuesen hombres enamorados de una mujer. Otras optan por la ambigüedad y se dirigen a un genérico tú. Un tercer grupo elige la égloga como molde poético" (MV3ESO, 131). Si la comparamos con San Juan de la Cruz y Fray Luis de León, es decir, en los escritores que acompañan en las páginas del libro de texto a Santa Teresa de Jesús, observamos que la longitud y el tratamiento son similares, con la salvedad de que sí aparecen tres textos en esas páginas de los dos poetas: la "Oda a Francisco Salinas" y "Al salir de la cárcel”, de Fray Luis de León, y "En una noche oscura», de San Juan de la Cruz. Más adelante, el conocido poema "Vivo sin vivir en mí...", de Santa Teresa de Jesús, es incluido en una serie de actividades propuestas a partir de obras originales de Fernando de Rojas, Garcilaso de la Vega, Santa Teresa de Jesús y Juan de Mena (MV3ESO, 135-136).

Finalmente, en la "Unidad 9. El Barroco (Siglo XVII)» nos encontramos en unas actividades planteadas con el poema "Contiene una fantasía contenta con amar decente", de Sor Juana Inés 
de la Cruz (MV3ESO, 152). Es curiosa su inclusión si tenemos en cuenta que en ningún otro momento del libro de texto la escritora latinoamericana ha sido siquiera citada, como sí lo han sido otros escritores del periodo como Luis de Góngora, Francisco de Quevedo y Lope de Vega (MV3ESO, 145).

Es sintomático que en el caso de Santa Teresa se incida en su condición de mujer y en su carácter de supuesta iniciadora de la escritura de mujeres en el siglo XVI, lo cual no se destaca en ninguno de sus contemporáneos. Esta sutil diferencia tiene mucho de ideológica, según la concepción althusseriana, y de discurso marcado por la dominación masculina, de la que hablaba Bourdieu, en el sentido de que lo masculino ha sido ubicado como el término no marcado de la matriz, mientras que lo femenino ha sido dispuesto como el término marcado de la misma, es decir, el concepto subordinado sobre el que la crítica ha naturalizado la necesidad de remarcar su carácter diferenciado. Lo propio, lo natural, es lo masculino; lo otro, en un sentido peyorativo del término, es lo femenino.

En ambos casos, su pertenencia al estamento clerical les dio la opción de poseer el espacio, el tiempo y la formación necesaria para la elaboración y publicación de sus escritos, a pesar de que tuvieran que recurrir durante sus vidas al favor de los varones para la publicación de sus obras: Fray Luis de León, por ejemplo, fue el editor de Las moradas de Santa Teresa cuando ejercía en su cátedra de Sagrada Escritura en la Universidad de Salamanca; Sor Juana Inés, que tenía estrechas relaciones con la corte del virrey Payo Enríquez de Rivera, dio a conocer su obra en España gracias al Obispo de Yucatán, que favoreció su publicación en la Península. Y es que "en el discurso eclesiástico la superioridad del varón se remonta a la interpretación de la historia de la creación divina de la raza humana, fundamentada en la exégesis bíblica que hace de ella primero San Pablo y luego los Padres de la Iglesia" (Lacarra, 1995: 22). Sin embargo, estos detalles se invisibilizan en los manuales de la ESO de la Marea Verde, aun cuando son centrales para entender por qué ambas escritoras consiguieron participar en los procesos de canonización, a diferencia de muchas de sus contemporáneas.

Vayamos ahora a las ausencias. No se incluye ni se nombra en las páginas correspondientes a esta época de la literatura a ninguna otra mujer escritora en ninguno de los libros de texto analizados, pese a que muchas (fuera o dentro del ámbito de la Iglesia) tuvieron la ocasión de escribir y publicar textos de indudable calidad: María de Zayas, Sor Agreda, Ana de Castro Egas, Ana de Caro Mallén, Mariana de Carvajal, etc. Son estos algunos nombres que injustamente no aparecen en las historias de la literatura de mayor recorrido y que, por supuesto, tampoco lo hacen en los manuales de la ESO. Ya en su momento, alguna de ellas alzó la voz en contra de esta reclusión, pero poco o nada cambió su situación. Vale la pena, sin embargo, recordar aquellas palabras de María de Zayas:

La verdadera causa de no ser las mujeres doctas no es defecto de caudal, sino falta de aplicación, porque si en nuestra crianza, como nos ponen el cambray en las almohadillas y los dibujos en el bastidor, nos dieran libros y preceptores, fuéramos aptas para los puestos y para las cátedras como los hombres y quizás más agudas por ser de natural más frío. (Zayas, 2012: 362)

Si continuamos con el análisis, hay un absoluto vacío entre Sor Juana Inés de la Cruz y Rosalía de Castro, que es la siguiente autora citada ya en Lengua y literatura castellana 4. ESO, dentro del apartado dedicado a la lírica "Unidad 7: Siglo XIX y principios del siglo XX". De esta forma, quedan acalladas las voces de centenares de escritoras de suma importancia para comprender los desarrollos de la historia de las letras hispanas (Sullivan, 1997: 305-330), sobre las cuales nada podrá conocer el alumnado al que van dirigidos. El discurso patriarcal vuelve a hacer acto de presencia en el escueto párrafo bibliográfico dedicado en el anexo "Saber más" a Rosalía de Castro. Sintomáticamente, en él se utiliza el concepto "poetisa", sin hacer referencia a la amplia problemática sobre el mismo que ha recorrido la historia literaria española, y se habla de su 
maternidad y su matrimonio: "Es una poetisa que tuvo una vida triste (hija ilegítima, huérfana, muerte de un hijo, matrimonio infeliz" (MV4ESO, 98), mientras que en ninguna de las semblanzas sobre sus contemporáneos (Espronceda y Bécquer) encontramos ninguna referencia a sus parejas o a su condición (o no) de padres. A su vez, una obra de Rosalía de Castro forma parte de unas actividades posteriores (MV3ESO, 106), rodeada de textos de escritores varones: Larra, Espronceda y Juan Ramón Jiménez.

Ahora bien, la reseña de Rosalía de Castro no evita que se continúe reproduciendo inconscientemente (o no, nos es imposible averiguarlo) la matriz de dominación que en estas páginas venimos destacando. Por una parte, a Espronceda se le trata como el "prototipo de persona romántica. Su vida estuvo llena de acontecimientos propios de esta época (exilio, rapto de una mujer, actividades clandestinas" [MV4ESO, 98]). Por otra, sobre Rosalía de Castro se había focalizado en la tristeza que recorrió su vida y en su papel subordinado con respecto a su matrimonio y su maternidad. Es decir, la imagen de Espronceda responde al patrón masculino de ser activo y abierto hacia lo público, mientras que el de Rosalía responde al patrón femenino de ente pasivo y encerrado en el espacio de lo privado. Así pues, incluso cuando se equiparan en un mismo nivel de importancia en el libro de texto, la obra y la vida de un hombre como Espronceda y la de una mujer como Rosalía de Castro se reproducen las divisiones constitutivas del orden social, así como las relaciones de dominación y de explotación históricamente avaladas:

Corresponde a los hombres, situados en el campo de lo exterior, de lo oficial, de lo público, del derecho, de lo seco, de lo alto, de lo discontinuo, realizar todos los actos a la vez breves, peligrosos y espectaculares, que, como la decapitación del buey, la labranza o la siega, por no mencionar el homicidio o la guerra, marcan unas rupturas en el curso normal de la vida; por el contrario, a las mujeres, al estar situadas en el campo de lo interno, de lo húmedo, de abajo, de la curva y de lo continuo, se les adjudican todos los trabajos domésticos, es decir, privados y ocultos, prácticamente invisibles o vergonzosos, como el cuidado de los niños y de los animales, así como todas las tareas exteriores que les son asignadas por la razón mítica, o sea, las relacionadas con el agua, con la hierba, con lo verde (como la escardadura y la jardinería), con la leche, con la madera, y muy especialmente los más sucios, los más monótonos y los más humildes. (Bourdieu, 2000: 45)

A continuación, en el apartado dedicado a "El realismo y el Naturalismo" el libro de texto sobrevuela en unos breves párrafos a Benito Pérez Galdós, Clarín, Vicente Blasco Ibáñez y Emilia Pardo Bazán, sobre la que afirman: "Una escritora brillante, con una gran cultura, que desempeñó varios cargos culturales. Escribió La cuestión palpitante (trata de conciliar las ideas del Naturalismo con el cristianismo). Novelas importantes: Los pazos de Ulloa y La madre naturaleza (relata la degeneración y la ruina progresiva de una familia aristocrática)" (MV4ESO, 101). Son estas las únicas líneas dedicadas, además de una pregunta en las actividades de esa misma página en la que se pide al alumnado que realice una búsqueda en la biografía de Pardo Bazán para descubrir si escribió algo más que novelas. Resulta curioso, en este sentido, que no se haga ninguna referencia a la férrea defensa de la emancipación de la mujer que realizó en vida la escritora y que, en gran medida, se plasmó en Las medias rojas.

Más allá de las cuestiones de género, tampoco se incide en los detalles de clase social: Pardo Bazán formaba parte de la nobleza gallega, lo cual no es siquiera indicado, como tampoco se focaliza en las puertas que eso pudo abrirle a una mujer del siglo XIX para hacerse un hueco en el campo literario de la época. El campo literario, vedado en muchas ocasiones a las clases menos pudientes, expulsó de los procesos de canonización a los escritores, en una suerte de actitud clasista, y a las escritoras, por su doble condición de desigualdad en tanto mujeres y en la medida en que pertenecieron a una clase no burguesa. Así, han quedado fuera de los 
manuales las obras de autoras como Carolina Coronado, Josepa Massanés, Dolores Cabrera, Rosa Butler, Amalia Fenollosa, Teresa Claramunt,, etc, tal y como destacaron en diversos estudios Blanca (1998), Hurtado (1998), Kirkpatrick (1998) o Laura Vicent (2011) en su reivindicación a modo de historiografía literaria.

En la "Unidad 8. La literatura del siglo XX (hasta la década de los 60)", únicamente son citadas tres escritoras: María Zambrano (MV4ESO, 117) en el subapartado de "Literatura en el exilio"; Ana María Matute (MV4ESO, 118) y Carmen Martín Gaite (MV4ESO, 118) en el anexo "Saber más" del apartado "Literatura durante el franquismo II": "La Colmena de Cela, Las ratas de Miguel Delibes, Entre visillos de Carmen Martín Gaite o Primera memoria de Ana María Matute son las novelas sociales más destacadas de esta década" (MV4ESO, 118). Frente a ello, en "Literatura en el exilio" son citados Alberti, Francisco Ayala, Alejandro Casona, Max Aub, Cernuda y León Felipe (de estos dos últimos, además, se incluyen dos poemas); en "Literatura durante el franquismo II" son citados Sánchez Ferlosio (junto a un extracto de El Jarama), Camilo José Cela (junto a un extracto de La Colmena y de La familia de Pascual Duarte) (ambos en MV4ESO, 118-120), Luis Martín-Santos, Torrente Ballester, Juan Benet, Juan Goytisolo, Juan Marsé y Miguel Delibes, junto a un fragmento de Cinco horas con Mario (todos ellos en MV4ESO, 119). En este sentido, son completamente olvidadas María Teresa León, las poetas de la Generación del 27, la recientemente rescatada Luisa Carnés o las poetas del cincuenta, entre otras muchas.

En la "Unidad 9. Literatura hispanoamericana. La literatura española actual" se produce un considerable aumento en el número de autoras mencionadas, sin que ello suponga, sin embargo, una equiparación con los hombres ni cuantitativamente ni en al tratamiento recibido (en cuanto al lugar y forma de la mención). En el apartado dedicado a los narradores, encontramos reseñados en el cuerpo del texto a Jorge Luis Borges, Juan Rulfo, Julio Cortázar, Gabriel García Márquez y Mario Vargas Llosa. Por su parte, las escritoras son citadas en un lugar secundario, como anexo al cuerpo del texto bajo el rótulo "Saber más": "En la actualidad hay muchas escritoras hispanoamericanas que tienen un gran éxito entre los lectores de habla hispana. Algunos nombres son Isabel Allende (La casa de los espíritus), Marcela Serrano (Hasta siempre, mujercitas) o Gioconda Belli (El infinito en la palma de la mano)" (MV4ESO, 127). El libro de texto vuelve a colocar, por lo tanto, a los escritores en el centro de la historia literaria ofrecida al alumnado y desplaza a las escritoras hacia los márgenes. Un mecanismo similar es el utilizado en las páginas dedicadas a la poesía latinoamericana: entre la maraña de nombres masculinos, únicamente aparecen Alfonsina Storni (citada) y Gabriela Mistral (reseñada): "Seudónimo de Lucila de María del Perpetuo Socorro Godoy Alcayaga fue una poetisa, diplomática, feminista y maestra chilena. La primera latinoamericana galardonada con el Nobel de Literatura. Su poesía es intimista. En ella aparecen numerosas referencias a los niños" (MV4ESO, 128). De nuevo, se utiliza sin debate previo el rótulo "poetisa». En ese mismo apartado, son reseñados Octavio Paz, Pablo Neruda, Mario Benedetti, Nicanor Parra y Nicolás Guillén. Las actividades siguientes únicamente se centran en obras escritas por hombres.

En las extensas listas de autoras y autores de la literatura española de los últimos años, tan solo son citadas las poetas Blanca Andreu, Juana Castro, Olvido García Valdés y Amparo Amorós (MV4ESO, 130), mientras que de Ana Rossetti aparece un poema original en el marco de unas actividades (MV4ESO, 134). Ninguna narradora ni dramaturga aparece en unos listados copados por escritores: Javier Marías, Eduardo Mendoza, Julio Llamazares, José María Merino, Antonio Muñoz Molina y Javier Torneo, como narradores, y Francisco Nieva, José Sanchis Sinisterra, Fernando Fernán Gómez, José Luis Alonso de Santos y Fermón Cabal, como dramaturgos. Sin ánimo totalizador, quedan relegadas reconocidas autoras como Carme Riera, Cristina Fernández Cubas, Rosa Montero, Sara Mesa, Marta Sanz, Carmen Amoraga, Maruja Torres, Paloma DíazMas, Adelaida García Morales, y un larguísimo etcétera. No hemos destacado aquí a Almudena Grandes, que es únicamente citada (MV4ESO, 132), ni a Carmen Gómez Ojeda, puesto que un 
fragmento de Cantiga de agüero forma parte de los comentarios de textos propuestos en el anexo de literatura (MV4ESO, 166-167). Tampoco a la mexicana Laura Esquivel, incluida en los anexos a partir de un breve fragmento de Como agua para chocolate (MV4ESO, 164-165).

Llegados a este punto, conviene destacar que los ejercicios que plantean los libros de texto de la Marea Verde en relación con la figura y la representación de las mujeres aparecen tan solo en aquellas páginas dedicadas al estudio de la obra y la vida de las mujeres escritoras y, en ningún caso, vinculadas con los textos de los autores. Implícitamente, como ha ocurrido a lo largo de la historia, la problemática sobre el papel de las mujeres queda recluida a los textos escritos por ellas mismas, como si únicamente pudieran ser representadas en las ficciones escritas por mujeres y como si los hombres nada tuvieran que ver en esta historia. Se elimina así una parte fundamental de la cuestión, que es absolutamente necesaria para comprender de qué forma han sido tratadas las figuras femeninas en las ficciones a lo largo de la historia y, por lo tanto, para comprender los diferentes discursos ideológicos. En este sentido, tanta importancia tiene saber de qué forma, por ejemplo, Emilia Pardo Bazán o Rosalía de Castro representaban a las mujeres en sus obras, como saber de qué manera eran tratadas por Galdós o Clarín, al igual que conocer de qué forma ellas y ellos han representado las figuras masculinas. Así pues, un manual que quiera tender en sus páginas a la igualdad y la inclusión es necesario que afronte el problema desde esta visión múltiple para captar con el mayor detalle una fotografía de conjunto que nos permita acceder a él a partir de las distintas ópticas, capas y discursos que lo forman.

\section{Conclusiones}

Finalmente, y con los datos y análisis textuales en la mano, parece claro que los libros de la Marea Verde perpetúan una visión de la historia de la literatura española que ha sido constituida a partir de la matriz de la dominación masculina definida por Bourdieu. No es, como se ha visto, un hecho aislado, sino un ejemplo más en la amplia constelación de libros de texto que siguen las mismas direcciones. La imagen que a través de estos cuatro libros de texto se ofrece al alumnado es la de una historia literaria escrita en masculino, en la que han sido los hombres quienes han ocupado los puestos centrales y de poder en el campo literario. Se reproduce así una ideología de la desigualdad que no se plantea la cuestión fundamental, ya comentada, sobre la necesidad de descolonizar, re-apropiar y re-escribir el canon del patriarcado, defendida por Iris Zavala (1993: 28), sino que la esquiva en una clara reproducción de la historia literaria oficial construida a partir de una visión patriarcal de la literatura, de la cultura y de la sociedad. Es fundamental, por tanto, plantear análisis críticos como el que aquí hemos desarrollado, para descubrir las lagunas y fallas de la historia literaria que nos narran los manuales de la ESO; con ello, será posible comenzar a proponer nuevos materiales educativos que se fundamenten en las más recientes teorías de género y que tengan en consideración a las autoras silenciadas por la historiografía literaria. Únicamente así podremos ofrecer al alumnado una fotografía más veraz e inclusiva, apoyada y reforzada en los artículos, estudios, análisis, ediciones o monografías que en fechas cercanas han reivindicado el papel de las mujeres escritoras en las diferentes épocas históricas. Erigir, al cabo, la voz desde el silencio.

\section{Referencias bibliográficas}

Adorno, T. y Horkheimer, M. (1988). Dialéctica del iluminismo. Buenos Aires: Sudamericana.

Althusser, L (1974). Ideología y aparatos ideológicos de estado: notas para una investigación. Barcelona: Seminario del Instituto de estudios Laborales.

Benjamin, W. (2003). La obra de arte en la época de su reproductibilidad técnica. México DF: Ítaca. 
Blanca, A. (1998). Escritora, feminidad y escritura en la España de medio siglo. En I. Zavala (coord.), Breve historia de la literatura feminista de la literatura española (en lengua castellana) V. La literatura escrita por mujer (del s. XIX a la actualidad), 9-37. Barcelona: Anthropos.

Blanco García, N. (2000). El sexismo en los materiales educativos de la ESO. Sevilla: Instituto Andaluz de la Mujer.

Bourdieu, P. (1994). Las reglas del arte. Génesis y estructura del campo literario. Barcelona: Anagrama.

Bourdieu, P. (2000). La dominación masculina. Barcelona: Anagrama.

Butler, J. (2006). Vida precaria. El poder del duelo y la violencia. Buenos Aires: Paidós.

Dubois, J. (2014). La institución de la literatura. Antioquía: Editorial de la Universidad de Antioquía.

Even-Zohar, I. (1991). Polysistem Studies. Volumen monográfico de Poetics Today. International Journal for Theory and Analysis of Literature and Communication, 11 (1).

Fariña Bustos, M.J. (2016). Feminismo y literatura. Acerca del canon y otras reflexiones. Revista de Escritoras Ibéricas, (4), 9-41. Disponible en: http://revistas.uned.es/index.php/REl/article/view/17479.

Firestone, S. (1976). La dialéctica del sexo. Barcelona: Kairós.

Foucault, M. (2006): Sobre la Ilustración. Madrid: Tecnos.

García Gracia, M. et al. (1993). El sexismo en los libros de texto: análisis y propuesta de un sistema de indicadores. Madrid: Ministerio de Cultura. Instituto de la Mujer.

García-Luque, A. (2016). La LOMCE bajo una mirada de género/s ¿Avances o retrocesos en el siglo XXI?. Revista de Educación Política y Sociedad, 1 (2), 100-124.

Garreta Torner, N. y Careaga Castrillo, P. (1987). Modelos masculinos y femeninos en los textos de EGB. Madrid: Ministerio de Cultura. Instituto de la Mujer.

Hurtado, A. (1998). Memorias y autobiografías escritas por mujeres. En I. Zavala (coord.), Breve historia de la literatura feminista de la literatura española (en lengua castellana) $V$. La literatura escrita por mujer (del s. XIX a la actualidad), 139-153. Barcelona: Anthropos.

Iglesias, M. (1994). "El sistema literario: Teoría Empírica de la Literatura y Teoría de los Polisistemas". En D. Villanueva (ed.), Avances en teoría de la literatura (Estética de la recepción, Pragmática, Teoría Empírica y Teoría de los Polisistemas), 309-3556 Santiago de Compostela: Universidad de Santiago de Compostela.

Instituto de la Mujer (2000). La transmisión de los modelos femeninos y masculinos en los libros de enseñanza obligatoria. Madrid: Instituto de la Mujer.

Kirkpatrick, S. (1998). “La tradición femenina en la poesía romántica». En I. Zavala (coord.), Breve historia de la literatura feminista de la literatura española (en lengua castellana) V. La literatura escrita por mujer (del s. XIX a la actualidad), 39-73. Barcelona: Anthropos.

Lacarra, M.E. (1995). "Representaciones de mujeres en la literatura española". En I. Zavala (coord.), Breve historia feminista de la literatura española (en lengua castellana). II. La mujer en la literatura española, 21-67. Barcelona: Antrhropos. 
López-Navajas, A. (2014). Análisis de la ausencia de las mujeres en los manuales de la ESO: una genealogía de conocimiento ocultada. Revista de Educación, (363), 282-308. Disponible en: $\quad$ https://www.educacionyfp.gob.es/dctm/revista-deeducacion/articulos363/re36312.pdf?documentld=0901e72b817fcfba.

López-Navajas, A. (2015). Las mujeres que nos faltan. Análisis de la ausencia de las mujeres en los manuales escolares. Tesis doctoral. Valencia: Universitat de Valencia.

Nash, M. (2004). Mujeres en el mundo. Historia, retos y movimientos. Barcelona: Alianza Editorial.

Quiceno, H (2001). El manual escolar: pedagogía y formas narrativas. Revista Educación y Pedagogía (29/30), 53-67. Disponible en: https://aprendeenlinea.udea.edu.co/revistas/index.php/revistaeyp/article/viewFile/750 $\underline{6 / 6909}$

Russ, J. (1983). How to Suppress Women's Writing. Austin: University of Texas Press.

Sullivan, Constance A. (1997): Las escritoras del siglo XVIII. En I. Zavala, (coord.), Breve historia feminista de la literatura española (en lengua castellana). IV. La literatura escrita por mujeres de la Edad Media al siglo XVIII, 305-330- Barcelona: Anthropos.

Vicent, L (2011). Matrimonio, familia y estado: escritoras anarco-feministas en la Revista Blanca (1898-1936). Madrid: Fundación Anselmo Lorenzo.

VV.AA. (2015a). Lengua y literatura 3을. Madrid: Marea Verde.

VV.AA. (2015b). Lengua y literatura 4을 ESO. Madrid: Marea Verde.

VV.AA. (2017a). Lengua y literatura 1ㅇ ESO. Madrid: Marea Verde.

VV.AA. (2017b). Lengua y literatura 2을. Madrid: Marea Verde.

Zavala, I (1993). Las formas y funciones de una teoría crítica feminista. Feminismo dialógico. En M. Díaz Diocaretz, e I. Zavala (coords.), Breve historia feminista de la literatura española (en lengua castellana). I Teorías feministas: discursos y diferencias, 27-76. Barcelona: Anthropos.

Zavala, I. (1995). "El canon, la literatura y las teorías feministas". En I. Zavala (coord.), Breve historia feminista de la literatura española (en lengua castellana). II. La mujer en la literatura española, 9-19. Barcelona: Antrhropos.

Zavala, I. (2002). “De la pluralidad de los cánones y la imposibilidad de lo Uno”. La Página, (48), 3-14.

Zayas, M. (2012). Novelas amorosas y ejemplares. Lemir (16), 353-572. Disponible en: http://parnaseo.uv.es/Lemir/Revista/Revista16/Textos/04 Zayas.pdf. 